\title{
Competence - Based Learning in the Romanian Higher Education: Perceptions from the
} Inside

\author{
Adela Coman \\ -Associate professor- The University of Bucharest, Romania
}

Catalina Bonciu

-Professor- The University of Bucharest, Romania

\begin{abstract}
This study aims to address the problem of competencies offered by the Romanian universities, from the perspective of the players interested in them and present on the labor market: post-university graduates and employers, as competencies' beneficiaries. We started from the premise that postgraduate studies can make a difference in a changing labor market, and the Master specializations offered by the Romanian universities can provide the competencies required by the employers, particularly in the business world. Our exploratory research aimed mainly to clarify the following aspects: the perception of post-university graduates on the competencies acquired and the perceived level of these competencies; if there is a link between the postgraduate programme and the job currently held by the graduate; if graduates are satisfied /dissatisfied with their job and what is the main reason for satisfaction / dissatisfaction; if the competencies provided by the university coincide with the competencies required by the employer. The results of the research showed that there are categories of competencies perceived to be deficient, both by graduates and employers. However, the graduates declare that, broadly, they are satisfied with their jobs, the reasons not being linked, in most cases, with their level of competence.
\end{abstract}

Keywords: competencies, human capital, postgraduate studies, suitability

\section{Introduction}

The transformation of all European higher education systems during the recent years has been characterized by an increase in the number of students in undergraduate and graduate courses, the introduction of policies and procedures for quality assurance in higher education and adapting the university curriculum to the requirements of the new economy and of the labor market.

These transformations have led to the restructuring of the higher education model. One of the most important trends was the shift from the traditional model based on transmitting information to a model which supports the development of competencies and a more active involvement of the student.The introduction of a competency-based approach in defining the outcomes of education is probably the most important feature of the university reform, and is closely linked to the need of increasing the students' employability. An individual is considered employable if he/she proves to have enough professional skills/competencies required by the labor market or by the changes which occur at the job, where these competencies are capitalized (Villa, Garcia Aracil, Mora, 2007). The notion according to which enterprises need well trained graduates who also possess a set of basic competencies (e.g. teamwork, initiative, problem-solving) which allows them to adapt to change, has become increasingly important. Yet this process has neither been easy, nor has it been simple, due to the confusion arisen with regard to what needs to be taught, the manner in which knowledge should be transmitted and how it should be evaluated (Green, Hammer, Star, 2009). 
This paper is structured in four sections: the first refers to the theoretical frame, in the broader context of the debate about the relationship between education and employability, which also allows foreshadowing the purposes of this study. The second section includes a description of the objectives pursued, the work methodology and some characteristics of the studied sample. The third section contains the results of the research and their interpretation. In the last section are presented an overview of the results, the implications, as well as the conclusions of the study.

\section{A literature review}

What particular competencies should be developed during undergraduate and graduate studies? This is a key issue which raises several questions: (1) how do we define "competencies"; (2) what are the basic competencies and what are the specific competencies for each field of study; (3) what are the real possibilities to teach certain competencies in university; (4) what is the relevance of the various types of learned competencies from the perspective of finding a job.

As regards the term "competency", it was defined as one's ability to pronounce oneself on something, based on a deep knowledge of the issue in question (DEX online). According to David McClelland (1973), competency refers to the sum of knowledge, skills and attitudes that contribute to a person's ability to effectively carry out (to standards previously agreed upon) his/her job tasks and responsibilities (in short, to be efficient). Competencies can be defined and developed.

In this paper, we define competencies as a set of knowledge, skills and expertise that individuals and organizations possess. These may be perceived as a set of learnt skills and abilities to perform specific activities based on a certain level of past experience. Hence, competencies are a product or a result of a process which individuals and organizations must undergo (a training programme or a series of tasks). Specialized literature, generally, identified different types of competencies, such as: management, science, technology, engineering and mathematics competencies (STEM) and social and communication competencies (Curtin et al, 2011; Smith et al, 2012).

Basic competencies are considered to be discrete entities which are measurable, transferrable and decontextualized from the fields of study (Mora, 2007). The discussion regarding competencies considered as the most important and the reason why they hold this status (basic competencies versus specific competencies) actually start from the dilemma of competence-based education which ensures the flexibility and adaptability of graduates throughout their lives - basic compencies - versus the education based on specific competencies, intrinsically linked to the field of study (Green, Hammer, Star, 2009; Heijke et al, 2003). More recently, the so-called soft skills were brought into discussion; these include: social intelligence and proactivity, the ability to search for and find information, to maneuver large databases. These soft skills are associated to the new jobs in the economy of knowledge and increased requirements of employers with regard to the performance of young employees.

The construction of competencies, on the other hand, is the formal or informal development process or the acquisition of specific competencies by individuals or organizations. Many specialists, in fact, agree with the idea that the innovative performance of an economy is largely dependent on the learning process of organizations and inviduals, as their constant ability to adapt and change in relation to the external environment changes, taking as a starting point precisely these skills. The motivation behind this focus on competencies and construction of competencies is based on accepting the fact that individuals and organizations must be able to adapt to the everchanging conditions. Therefore, in order to remain competitive, both individuals and organization must continually improve their competencies portfolio and constantly build/acquire new competencies.

If a company's competencies are embedded in its processes and are known, generally, as structural capital, in the case of individuals, acquiring competentices means acquiring information, knowledge, understanding and skills by participating in a type of formal (educational institution) or informal education (e.g. "seeing and doing"). The outcome of individual competency contruction is materialized in what we call today a (bigger) stock of human capital.

Certain authors draw the attention upon the fact that these competencies are hard to learn in the university environment, and that they can only be assimilated at the job. Heijke et al (2003) has proven that leadership and management competencies, such as creative problem solving, conflict negotiation and delegation of tasks are difficult to acquire outside a job. 
According to the human capital theory (Becker, 1964), investment in education increases an individual's labor productivity and is rewarded by higher wages. Therefore, people entering the labor market should invest more in their education, as a long-term strategy. This theory is based on other studies regarding the positive correlation between the level of education and the wage level throughout the entire life. This suggests that, in situations where there is a shortage of workforce and a high level of competition, those who invest more in their own education, as a differentiation strategy, shall record higher revenues/earnings. In the current conditions of higher education massification, when an increasing number of people are considering university studies, the differentiation between the members of this group shall be determined by the access to postgraduate education (specialization courses, master programs, doctorate), assuming that there is a certain homogeneity among individuals with the same qualification in terms of knowledge and skills acquired, and having a postgraduate certification will be better rewarded on the market (Flores Lagunes, Light, 2009).

However, there are problems regarding the human capital theory, problems related to the difficulty in proving that the growth in productivity of the most qualified workers stands precisely in their education. Productivity is unknown to employers when these qualified applicants enter the labor market. In the current situation, when acccess to university education is (almost) unlimited, we do not know with certainty that the mere fact of spending more years in university makes one more productive (Dobbs, Sun, Roberts, 2008). It should also be taken into account the fact that people continue to study not only for economic reasons, but also to have access to more interesting jobs, to develop their skills and to acquire more knowledge and / or social recognition.

The emergence of credentialism theories (Arrow, 1973; Spence, 1973;Taubman and Wales, 1973; Stiglitz, 1975), as an alternative theory to the human capital theory, has given the higher education institutions a classification and selection function. It was assumed that the purpose of education was not to provide knowledge or skills designed to increase the productivity of individual (since this productivity is obtained after employement), but to certify individuals' skills, adaptability and learning abilities. Consequently, education was considered to be a filter to identify individuals with the best qualities in terms of their employability and to qualify them in the best conditions for preliminary and internal training courses. Starting from these premises, the hypothesis that postgraduate studies have an additional, intrinsic value, beyond the number of years spent in universities, is sustainted, thus creating the perception of an increased productivity (Dobbs et al, 2008).

Both theories - human capital theory and credentialism theory - predict a better position for those who have completed some form of postgraduate studies (specialized studies, master or doctorate), as a strategy (of investment in education) designed to provide an increased degree of employability. Moreover, the credentialism approach says that a master and a doctoral program represents a greater competitive advantage than other postgraduate programs or training courses that are not recognized through a university diploma.

Following this approach, one of the objectives of this study was to examine the function of postgraduate studies (master programs) to increase the employability and competitiveness of graduates of such programs, wheather the competencies acquired (as students of master programs) coincide with the competencies required at the work place.

In the next section are presented the research objectives, the methodology as well as the characteristics of the sample.

\section{Research objectives}

The objective of our research was to provide an answer to the following questions:

(1) What is the perception of MA graduates regarding the competencies acquired and the level of such competencies?

(2) Is there a link between the attended postgraduate program and the currently held position?

(3) What is the level of satisfaction of MA graduates in their current job?

(4) What are the main competencies required by the employer at the current job? 


\section{Methodology}

Our research was carried out within a business faculty in Bucharest. Of all the master programs, we selected those that were regarded as "popular" both by the students and by the members of the teaching staff. More specifically, we approached those programs that had the highest enrollment rate during the two analyzed years - 2010-2011 and 20132014, namely a master degree in human resources (HR), a master degree in communication and public relations (PR) and a master degree in business management and administration (MBA). Our aim was to find out if there were any significant differences in terms of the competencies acquired by the students of the three classes which were analyzed, as well as the extent to which there exists a correlation between these competencies and the requirements of the labour market.

This being an exploratory research, we designed a questionnaire with 20 questions aimed especially at the students' perception as to the degree to which 5 categories of competencies are assimilated: management competencies (decisionmaking, problem solving, creativity, leadership, teamwork), communication competencies (written communication, verbal communication and online communication), general academic competencies (critical thinking, research abilities), instrumental competencies (computational abilities, foreign languages), theoretical and practical competencies (assimilating theoretical concepts and practical skills).

The approach of competencies analyzed in this study combine the traditional perspective of university education (questions related to the theoretical and practical knowledge specific to the classical academic education) with questions about competencies specific to the $20^{\text {th }}$ century, such a teamwork, creativity, problem solving and leadership, among others. This combination allowed us to make an assessment of the changes (however small) that occurred during the two periods under review, as a result of social pressure and the adjustment of the Romania education to the European higher education.

In order to ensure comparability of data, we administered these questions to 100 graduates of master programmes from each domain. We would like to mention the fact that the gender proportion was approximately the same in both intervals, namely $60 \%$ female and $40 \%$ male. The condition necessary for graduates to participate in the research was that they be graduates of the courses of at least one of the master programmes envisaged, and be employed.

\section{Results}

\section{The graduate's perception as to the level of competencies obtained during postgraduate courses}

In this section we approached two aspects: firstly, we identified which of the analyzed competencies records a deficit in the sense of the existence of a need which is not covered by such competencies; or the existence of a surplus of competencies in relation to what graduates are required at the job. Secondly, we sought to highlight the existence of change as to the manner in which students perceive these deficits/surpluses of competencies during the two analyzed periods. Thus, we proceeded with the differentiated analysis of the students' perceptions in each individual domain (HR, PR and MBA) and for each period (2010-2011 and 2013-2014). The results are presented in tables 1, 2 and 3.

\section{Table no. 1. The perception of master students in HR on the deficit/surplus of competencies (MU=\%)}

\begin{tabular}{|c|c|c|c|c|c|c|}
\hline HR Competencies & $\begin{array}{l}\text { Deficit } \\
2014\end{array}$ & Surplus 2014 & No disparity & $\begin{array}{l}\text { Deficit } \\
2010\end{array}$ & $\begin{array}{l}\text { Surplus } \\
2010\end{array}$ & No disparity \\
\hline Decision-making & 39 & 34 & 27 & 45 & 42 & 13 \\
\hline Problem solving & 67 & 22 & 11 & 54 & 37 & 9 \\
\hline Leadership & 48 & 35 & 17 & 42 & 40 & 18 \\
\hline Creativity & 72 & 12 & 16 & 65 & 13 & 22 \\
\hline Teamwork & 38 & 32 & 30 & 35 & 29 & 36 \\
\hline Written communication & 27 & 45 & 28 & 33 & 41 & 26 \\
\hline Oral communication & 32 & 42 & 26 & 39 & 38 & 23 \\
\hline Online cooperation & 52 & 33 & 15 & 59 & 30 & 11 \\
\hline Critical thinking & 50 & 29 & 21 & 42 & 32 & 26 \\
\hline Research abilities & 62 & 25 & 13 & 55 & 28 & 17 \\
\hline Computer abilities & 47 & 26 & 27 & 42 & 30 & 28 \\
\hline Foreign languages & 34 & 32 & 34 & 33 & 35 & 32 \\
\hline Theoretical concepts & 23 & 65 & 12 & 31 & 54 & 15 \\
\hline Practical abilities & 64 & 28 & 8 & 56 & 32 & 12 \\
\hline
\end{tabular}

Source: the authors' calculations 
It results that students perceive a deficit of competencies in the following domains: creativity (72\%), problem solving (67\%), practical $(64 \%)$ and research abilities (62\%) and online cooperation (52\%).

In 2010, competencies which recorded the highest deficit perceived by students were: creativity (65\%), problem solving $(54 \%)$, online cooperation (59\%), practical (56\%) and research abilities $(55 \%)$.

We can notice that, generally speaking, the deficit of competencies of the two generations of graduates is maintained, the same categories of competencies being envisaged. One can also notice that the above-mentioned deficit of competencies records a slightly growing trend in the class of 2014 as compared to the class of 2010.

The competencies that the HR graduates consider to be on the surplus are: the assimilation of theoretical concepts $(65 \%)$, written communication (45\%) and oral communication (42\%) in 2014. It is worth mentioning the fact that there exists a surplus of the above-mentioned competencies in 2010 , as well, namely $54 \%, 41 \%$ and $38 \%$ respectively, the tendency being a growth of the perceived surplus in 2014.

In table no. 2 are presented the perceptions of the Communication and Public Relations (PR) Master graduates regarding the degree of competency assimilation.

\section{Table no. 2. The perception of master students in PR on the deficit/surplus of competencies (MU=\%)}

\begin{tabular}{|l|l|l|l|l|l|l|}
\hline PR Competencies & $\begin{array}{l}\text { Deficit } \\
2014\end{array}$ & $\begin{array}{l}\text { Surplus } \\
2014\end{array}$ & No disparity & $\begin{array}{l}\text { Deficit } \\
2010\end{array}$ & $\begin{array}{l}\text { Surplus } \\
2010\end{array}$ & No disparity \\
\hline Decision-making & 35 & 36 & 29 & 32 & 33 & 35 \\
\hline Problem solving & 51 & 24 & 25 & 49 & 22 & 29 \\
\hline Leadership & 38 & 31 & 31 & 37 & 30 & 33 \\
\hline Creativity & 53 & 26 & 21 & 48 & 27 & 25 \\
\hline Teamwork & 31 & 33 & 36 & 30 & 35 & 35 \\
\hline Written communication & 22 & 58 & 20 & 23 & 55 & 22 \\
\hline Oral communication & 25 & 55 & 20 & 28 & 53 & 19 \\
\hline Online cooperation & 31 & 35 & 34 & 29 & 36 & 35 \\
\hline Critical thinking & 58 & 22 & 20 & 55 & 24 & 21 \\
\hline Research abilities & 33 & 34 & 33 & 28 & 35 & 37 \\
\hline Computer abilities & 50 & 23 & 27 & 48 & 21 & 31 \\
\hline Foreign languages & 39 & 42 & 19 & 36 & 40 & 24 \\
\hline Theoretical concepts & 15 & 59 & 26 & 14 & 57 & 29 \\
\hline Practical abilities & 70 & 15 & 15 & 69 & 14 & 17 \\
\hline
\end{tabular}

Source: the authors' calculations

Graduates of the PR program perceive themselves as having a deficit in the following categories: critical thinking (58\%), creativity (53\%), problem solving (51\%) and computer abilities (50\%). These competencies are on the deficit both in 2014 and in 2010, the values of the perceived deficits recording a slightly growing trend. Unlike the graduates of HR, graduates of PR perceive the lack of practical abilities the strongest, approximately $70 \%$ of these considering that, generally speaking, they do not have practical abilities.

As regards the surplus of competencies, it is recorded in the following domains: assimilation of theoretical concepts (59\%), written communication competencies (58\%) and oral communication competencies $(55 \%)$. It is worth mentioning the fact that these competencies were considered to be on the surplus in 2010, as well (namely $57 \%, 55 \%$ and $53 \%$ respectively). One can also notice the fact that all other categories of competencies there is a relative balance between the number of individuals considering that those competencies are in the deficit and those who consider them to be on the surplus. Moreover, there are no significant differences between the two generations of students who took part in the survey.

In table no. 3 are presented the perceptions of the Business Administration Master graduates (MBA) regarding the abilities acquired.

Table no. 3. The perception of master students in MBA on the deficit/surplus of competencies (MU=\%) 


\begin{tabular}{|l|l|l|l|l|l|l|}
\hline MBA Competencies & $\begin{array}{l}\text { Deficit } \\
2014\end{array}$ & Surplus 2014 & No disparity & $\begin{array}{l}\text { Deficit } \\
2010\end{array}$ & $\begin{array}{l}\text { Surplus } \\
2010\end{array}$ & No disparity \\
\hline Decision-making & 49 & 24 & 27 & 48 & 25 & 27 \\
\hline Problem solving & 55 & 26 & 19 & 53 & 24 & 23 \\
\hline Leadership & 52 & 23 & 25 & 41 & 21 & 20 \\
\hline Creativity & 57 & 20 & 23 & 45 & 28 & 27 \\
\hline Teamwork & 20 & 56 & 22 & 23 & 52 & 25 \\
\hline $\begin{array}{l}\text { Written } \\
\text { communication }\end{array}$ & 33 & 32 & 35 & 34 & 36 & 31 \\
\hline Oral communication & 30 & 28 & 42 & 28 & 32 & 40 \\
\hline Online cooperation & 23 & 51 & 26 & 26 & 47 & 21 \\
\hline Critical thinking & 45 & 27 & 28 & 43 & 28 & 29 \\
\hline Research abilities & 48 & 19 & 33 & 47 & 16 & 37 \\
\hline Computer abilities & 46 & 24 & 30 & 49 & 20 & 31 \\
\hline Foreign languages & 23 & 25 & 52 & 26 & 20 & 54 \\
\hline Theoretical concepts & 22 & 50 & 28 & 28 & 42 & 30 \\
\hline Practical abilities & 65 & 21 & 14 & 63 & 20 & 13 \\
\hline
\end{tabular}

Source: the authors' calculations

Graduates of the MBA programme signal a deficit in the following competencies: creativity (57\%), problem solving (55\%), leadership (52\%), closely followed by decision-making (49\%), research abilities $(48 \%)$, computer abilities $(46 \%)$ and critical thinking (45\%). The same competencies are in the deficit in 2010, with the noteworthy exception of two of them, i.e. creativity and leadership, which recorded a visibly growing trend in 2014 (55\% as opposed to $45 \%$, and $52 \%$ as opposed to $41 \%$ respectively). All the other above-mentioned competencies do not record significant evolution in 2014 as compared to 2010. It is also worth mentioning the fact that there is quite a big number of respondents who consider that there is no disparity in terms of the research and the computational competencies (approximately 30\% both in 2014 and in 2010).

Equally interesting was the perception of MBA graduates regarding the "surplus" competencies. In this category they placed teamwork $(56 \%)$, online cooperation $(51 \%)$ and assimilation of theoretical concepts $(50 \%)$. These same areas have been indentified as surplus in 2010 ( $52 \%, 47 \%, 42 \%$, respectively). The other compencies, namely written communication, oral communication and foreign languages have an approximately equal distribution among respondents who consider them a deficit, a surplus or in the category "no disparity". As in the case of PR graduates, the MBA graduates consider they lack most the practical abilities (65\% in 2014 and 63\% in 2010).

Analyzing the data referring to the graduates' perception as to the competencies assimilated during their master studies highlights the fact that, in general, competencies which are perceived as being in the deficit by all graduates of the master degree programs approached are: creativity, problem solving and practical abilities. Graduates of two out of three programs also mention a deficit in terms of research abilities (HR and MBA), computational abilities and critical thinking (PR and MBA), and only one program mentions a deficit of competencies in leadership and decision-making (MBA).

As regards the surplus of competencies, all graduates of these programmes consider that assimilation of theoretical concepts is redundant. Graduates of two out of the three programs mentioned a surplus of competencies in written communication and oral communication (HR and PR), and the graduates of one program perceived teamwork and online cooperation as being in excess (MBA).

\section{The relation between the level of postgraduate education and the labor market}

One of the most important indicators of performance of higher education institutions is the degree of adequacy of the qualification obtained by the graduates and the characteristics of the job they hold.

To address the correlation between the level of education and the labor market we started by addressing two questions related to the current job (or, in some cases, the job graduates had after graduation). First, graduates were asked: "What were the requirements for obtaining the job you currently have/you had after graduation?" The following answers were considered: "They required higher education in the field", "They required only higher education", and "They did not require higher education". Then a second question, linked to the first, was asked, which offered two possible answers: if the job 
implies a certain specialization (master degree), graduates were asked if the degree program they had graduated from was a requirement for holding that position; and in case no specific specialization was required, if it was necessary to be a master degree graduate. In the table bellow we highlighted the results obtained resulting the combination of the following variants: (1) a specific master program/a set of competencies and requirements for the job linked to the specific mater program/the set of specific competencies; (2) a specific master program/a set of competencies not linked to the requirements of the job; (3) a non-specific master program to be correlated to specific competencies/job requirements; (4) a non-specific master program with competencies that are not job-specific (not correlated with the requirements of the job). We mention that the questions were addressed to all graduates, therefore the results relate to both generations analyzed. The results are presented in table no. 4:

Table no. 4. Relation between specialization (graduated master program) and the competencies required for the job

\begin{tabular}{|l|l|l|l|}
\hline $\begin{array}{l}\text { Specific master program and } \\
\text { specific competencies }\end{array}$ & $\begin{array}{l}\text { Specific master program and } \\
\text { non-specific competencies }\end{array}$ & $\begin{array}{l}\text { Master program and specific } \\
\text { competencies }\end{array}$ & $\begin{array}{l}\text { Master program and non- } \\
\text { specific competencies }\end{array}$ \\
\hline $32 \%$ & $30 \%$ & $26 \%$ & $12 \%$ \\
\hline
\end{tabular}

Source: the authors' calculations

In general, the figures show that the graduated master program is correlated to the competencies required for the position held, in $32 \%$ of the cases the requirement being for job specific competencies, and in other $30 \%$ - non-specific competencies.

The question "Do you think the master program you graduated from is relevant for the position you currently hold?" was answered in the affirmative by most graduates (85\% in 2014 and 78\% in 2010).

It should be noted that the occupational status of the MA graduate reflects not only the impact of university education, but also the interaction between this and the macroeconomic conditions - what organizations capitalize and search in a certain period of time - as well as the graduate's characteristics and qualities such as: work experience, effort invested in finding a job, etc. (Velasco, 2007). Therefore, we consider that the answers to the question above should be interpreted with caution, given that at the time of the study we did not have all the necessary information to formulate an opinion on the relevance of university and MA education for an extremely large variety of positions.

Graduates were then asked to evaluate on a scale from 1 (very low) to 5 (very high) their level of satisfaction with regard to job they currently hold.The degree of satisfaction was considered taking into account four elements: the content of the activity they perform, the promotion perspectives, the salary level, the use of knowledge assimilated during studies. The results are presented in table no. 5 :

Table no. 5. The MA graduates' perceived level of satisfaction

\begin{tabular}{|c|c|c|c|c|c|}
\hline & Very low & Low & Neutral & High & Very high \\
\hline Content of activity & 15 & 12 & 24 & 28 & 21 \\
\hline $\begin{array}{l}\text { Promotion } \\
\text { perspectives }\end{array}$ & 11 & 20 & 13 & 24 & 22 \\
\hline Salary level & 34 & 38 & 21 & 5 & 2 \\
\hline $\begin{array}{l}\text { Use of assimilated } \\
\text { knowledge }\end{array}$ & 26 & 22 & 16 & 31 & 5 \\
\hline $\begin{array}{l}\text { General satisfaction } \\
\text { level }\end{array}$ & 20 & 23 & 18 & 22 & 17 \\
\hline
\end{tabular}

Sourse: the authors' calculations

Analyzing the data, one can conclude that graduates of postgraduate study programs are satisfied with the content of the activity performed $(49 \%)$, they have promotion perspectives in their career (46\%), they consider useful $(31 \%)$, but not very useful $(5 \%)$ the knowledge accumulated during studies $(36 \%)$, but are dissatisfied with the salary level $(72 \%)$. Yet, the general satisfaction level is high (22\%) and very high (17\%). 
Specialized studies regarding the satisfaction level show that, in general, graduates are moderately satisfied with their professional status (Mora, Carbonell, 2009). Moreoever, as with salary incomes, the chosen specialization seems to be a determinant of satisfaction, along with the adequacy of education content compared to the job's structure and tasks (Mora, Carbonell, 2009). On the other hand, the disparity between the competencies provided by the university and the level of competencies required at the workplace does not seem to be a problem; on the contrary, it seems to have rather a positive impact on the level of satisfaction for the Romanian graduates. The idea of complex tasks at work involves a greater degree of satisfaction, perhaps because of the perception of a higher occupational status, and the motivation associated with jobs that require greater effort. This is connected to the professional and personal promotion associated to/offered by these workplaces (McGuiness, 2003).

\section{The relation between the complexity of the job held and the associated competencies from the employer's perspective}

Until now, the labor market needs have been evaluated using two complementary methodologies: (a) the first focused on the question directly addressed to the employer about the competencies that graduates should possess to obtain a qualified job; (b) the second focused on the way graduates perceive the usefulness of the competencies acquired, what should be their level and how relevant are these to obtain the target job.

With regard to the competencies required at the workplace, it is difficult to analyze the results obtained by different researchers because of the disparity between the conceptual and methodological criteria used and the social and economic context in which the research took place. There were examined different periods of time and, therefore, different needs and values required on the labor market. As observed by Davies et al (2013), having IT abilities in the ' 90 s was a competitive advantage, whereas today other competencies such as social intelligence, creativity, empathy, transdisciplinarity, intercultural competency, etc. are valued.

In this study, we referred to five categories of competencies and we asked the employers to rank them according to their relevance for the job held by the MA graduate. The ratings given by the employers were the following: management competencies (35\%), general academic competencies (22\%), communication competencies (16\%), theoretical and practical competencies (15\%) and instrumental competencies (12\%).

As regards management competences, one has to emphasize the fact that, from the perspective of the job they currently have, graduates experience a deficit in management competencies, in particular in the problem solving and creativity aspects. The deficit is perceived as less emphasized in regard to decision-making and leadership competencies. In this category, only the one related to teamwork is perceived as redundant, yet it is true that only to a small extent

As regards general academic competencies we can also speak about a deficit. Both critical thinking and research abilities are not mastered properly by the graduates of masters programs (2 out of 3 master programs), considering that these are required by employers and prioritized, according to importance, on the second place, after management competences.

The only category of competencies perceived by graduates as being delivered excessively in relation to the job held is the communication competency category. These are important for employers as well, $16 \%$ of them giving roughly equal degrees of importance to oral communication, written communication and online communication.

The theoretical and practical competences (15\%) are ranked, by importance, very close to the communication competencies. According to the analyzed data, the majority of the employers request graduates to both $\mathrm{know} / \mathrm{be}$ in control of some theoretical concepts and practical abilities necessary for the carrying out of some operations. From the graduates' perspective, the fact that they feel an excess of theoretical knowledge, on the one hand, and an accentuated deficit in practical abilities, on the other hand, is remarkable. This perception is common to graduates of all three master programmes, from both generations.

In the category of instrumental competences, knowledge of foreign languages is recognized as fairly important amongst employers. Alternatively, this competency is not perceived as essential by the graduates. As regards to computational abilities, the graduates of two out of three programs say that they feel a lack of such competencies, fact that could create problems for the employers that need employees able to operate large quantities of information and sophisticated databases. 


\section{Conclusions and implications}

The phenomenon of transforming the university education into mass education in the past years has led to a higher pressure on the qualified workforce and to a more severe competition for the graduates that enter the labor market. This situation determines higher education graduates ( 3 years) to continue their studies (through MA programs that add value to their professional training) in order to make a difference from their colleagues who do not do this.

Starting from these considerations, the aim of this study was to determine how the master program graduates relate to the delivered competencies, namely to analyze if there are differences that can be seen either as a deficit or as a surplus of the competencies offered through the graduated master programs. We also analyzed if there is a connection between the competencies delivered by the university and the ones required by the employers. In particular, we were interested in the degree of satisfaction perceived by graduates on the job currently held. Also, we wanted to see what are the competencies required by the employers, in general, in order to obtain a job that involves a master degree, and to what extent there is a discrepancy between the competencies provided by the university and those required by the employers. Several authors suggested that the discrepancy between the competencies obtained through university education and the ones required on the labor market is solved on the job through "on the job training" (Heiijke et al, 2003). The hypotheses that all these authors start from is that generic competencies which are taught in university do not have a direct influence on the results obtained on the labor market.

In the specific case of our research, the master program graduates noticed a lack of management competencies (problem solving, creativity, decision-making, leadership), i.e. exactly those skills that are required to the highest degree by employers. Also, according to the graduates' perceptions, there is also an important deficit in critical thinking competence and research abilities, competencies that are prioritized by employers as second, according to importance.

Paradoxically, the employed masters programs graduates declare that they are satisfied and very satisfied with the job they have, despite the fact that they do not consider useful $(31 \%)$ and not very useful $(5 \%)$ the knowledge/competencies assimilated and delivered to them by the master programs. The degree of satisfaction remains high even if the salary level is not as expected $(72 \%)$.

Briefly, the conclusions are the following: (1) competence-based education seems to have an impact on the labour market, although some of the competencies delivered are perceived as a deficit by their beneficiaries. In particular, we mean the management competencies (problem solving, creativity, decision-making, leadership) and the general academic competencies (critical thinking and research abilities); (2) the declared degree of satisfaction of these MA graduates does not seem to have a direct connection with the utility felt by them related to the competencies acquired and the level of such competencies. The satisfaction level is rather generated by the work content (job structure and tasks) and the prospects for professional development, promotion and career development; (3) there is a deficit of competencies also perceived/felt by the employers. We find interesting the fact that competencies such as creativity and problem-solving, for example, are on top of the competencies evaluated and required by employers to fill various positions.

We believe that in the future the focus should be on the fact that the main advantage a graduate brings on the labour market is his/her competence portfolio (a result of learning) in the guise of a specialization that defines his/her professional identity and the ability to carry out the taken assignments. And it is exactly this value of the competency portfolio that does not meet both the graduates' and employers' level of expectation. Competence assimilation (some of them difficult to assimilate in the university environment) represents only part of university education. From now on, we believe that the professionals in education should analyze not only the specific competencies of one specialization, but also the ones that are selected, promoted and searched for on the labor market for every profession. One should also check to what extent the selection and incorporation of new competencies in a certain field of study can lead to obtaining better jobs in terms of material and professional satisfaction. From this perspective, we consider that universities can and must make wise decisions regarding the selection and teaching of specific competencies for every field of study and specialization (this being an essential condition for the integration of the new graduates on the labor market).

On the other hand, businesses must be aware of the environment changes and adapt their strategies so as to include the need of future skills and competencies for jobs with greater complexity. HR professionals should reconsider traditional methods for identifying critical skills, as well as selection and talent development ones, since organizations need talent and 
new skills to reach their goals. A strategy regarding workforce in service of business sustainability should be one of the most important outcomes of HR professionals; but this strategy involves cooperation with universities in order to meet the longlife learning needs and learning/assimilation of new competencies and skills.

\section{References}

[1] Arrow, Kenneth: "Higher education as a filter", Journal of Public Economics, 2, 1973, pp. 193-216.

[2] Becker, Gary S.: "Investment in human capital: A theoretical analysis, Journal of Political Economy, 70, 1964, pp. 949.

[3] Curtin, Penelope/Stanwick, John/Beddie, Francesca: "Fostering enterprise: The innovation and skills nexus. Research readings", Adelaide, Australia: National Centre for Vocational Education Research, 2011.

[4] Davies, Anna/ Fidler, Devin/Gorbis, Marina: Future Work Skills 2020. Palo Alto, CA: Institute for the Future, http://www.iftf.org/our-work/global-landscape, accesat 14 Septembrie, 2015.

[5] Dobbs, Rita L./ Sun, Judy Y/ Roberts/Paul B.: "Human capital and screening theories: Implications for human resource development", Advances in Developing Human Resources, 10, 2008, pp. 788-801.

[6] Flores-Lagunes, Alfonso/Light, Audrey: "Interpreting degree effects in the returns to education", Journal of Human Resources, 45(2), 2010, pp. 439-467.

[7] Green, Wendy/ Hammer, Sarah/ Star, Cassandra: "Facing up to the challenge: Why is it so hard to develop graduate attributes?",Higher Education Research\&Development, 28(1), 2009, pp. 17-29.

[8] Heijke, Hans/Meng, Christoph/Ramaekers, G.: "An investigation into the role of human capital competences and their pay-off", International Journal of Manpower, 24, 2003, pp. 750-773.

[9] McClelland, David C.: Education for Competence. In H. Heckhausen and W. Edelstein (Eds), Proceedings of the 1971 FOLEB Conference, Berlin, Germany: Institut for Bildungforschung in der Max-planckGessellschaft, 1973.

[10] McGuinness, Seamus: "University quality and labor market outcomes", Applied Economics, 35(18), 2003, pp. 19431955.

[11] Mora, Toni/Ferrer-i-Carbonell, Ada: "The job satisfaction gender gap among young recent university graduates", The Journal of Socio-Economics, 38(4), 2009, pp. 581-589.

[12] Salas-Velasco, Manuel: "The transition from higher education to employment in Europe: The analysis of the time to obtain the first job", Higher Education, 54, 2007, pp. 333-360.

[13] Smith, A, et al.: "Building the capacity to innovate: The role of human capital", Adelaide, Australia: National Centre for Vocational Education Research, 2012.

[14] Spence, Michael A.: "Job market signaling”, Quarterly Journal of Economics, 87(3), 1973, pp. 355-374.

[15] Stiglitz, Joseph, E.: "The theory of screening, education, and the distribution of income", American Economic Review, 65(3), 1975, pp. 283-300.

[16] Taubmann, P. J., Wales, T. J.: "Higher education, mental ability and screening", Journal of Political Economy, 81, 1973, pp. 28-65.

[17] Vila, Luis E., Garcia Aracil, Adela, Mora, Jose-Gines: "The distribution of job satisfaction among young European graduates: does the choice of the study field matter?", The Journal of Higher Education, 78(1), 2007, pp. 97-118. 